\title{
Analysis of Reinforced Concrete Intze Water Tank with Different Staging Heights in Different Seismic Zones
}

\author{
Rakesh Yadav
}

\begin{abstract}
RC intze water tanks are constructed for storage and suppling of water through a certain height with adequate pressure of water distribution. Many overhead water tanks affected due to certainty like earthquake that can induce large lateral forces. So, there is a necessity to Understand and examine the behavior of intze tank supported on framing in context to different soil types under the seismic forces. This paper evaluates the experimental output of seismic analysis that compares shear and moments at base and also hydrodynamic pressure at wall and base slab for various seismic zone and different type of soil condition at different staging heights.
\end{abstract}

Keywords: Intze water tank, Seismic analysis, Base shear, Base moment. Hydrodynamic pressure, Staging height.

\section{INTRODUCTION}

Water supply plays a portal vote day to day life and adequate storage is highly desirable, is proportional to increase in population, requirement for daily utilities of people and also due to a improper distribution of electricity at various regions of India, it is so tough to supply water through the pipes and pumps at peak hours. So, at such scenario water tanks happen to vital part of life [1]. Earthquakes affected several tanks in past that can induce large seismic and gravity forces in elevated water tanks. The elevated water tank gets collapse due to a large mass concentrated at the top of the relatively slender system of supporting arrangements [2-3]. Water tanks can distress in different situations like inaccurate structural configuration design, poor materials quality and workmanship, corrosion of reinforcement, wind forces and earthquake [4].

\section{LITERATURE REVIEW}

Harsha et al. [7] analyzed and designed Intze water tank by considering the quake forces as per IS 3370-2009 and draft code IS 1893(Part-2): 2002 with two mass model i.e. impulsive model and convective model.

They observed that time period; base shear and moment determined by convective mode of vibration was greater as compared to the impulsive mode of vibration. Shear and moment at base by two mass model modes were obtained $36 \%$ and $41 \%$ respectively as compared to the lumped mass model method.
Livaoglu and Dogangun [8] they used finite elements model with the frame type and shaft type supporting system. It has been observed that the supporting system affect the sloshing displacement as compared to shaft type system. It was found that the displacement decreased $83 \%$ for frame type supporting system. However, $12 \%$ displacement decreased, when the shaft type supporting system is used.

Shakib et al. [9] analyzed RC elevated water tanks, having capacity of 900 cum and at a height of staging 25, 32 and 39 $\mathrm{m}$. It is assumed that concrete behaves nonlinearly. So, study entailed the shear and moment at base increases in the range between 10-20 \%, and 13-32 \% respectively. Also, displacement and hydrodynamic pressure increases in the range between $10-15 \%$ and $8-9 \%$, respectively.

Vyankatesh and Varsha [10] analyzed the circular Intze tank supported on RC frame staging and shaft staging at different staging height for different capacities and seismic zones for IS 1893 (Part-II):2014, is derived the increase in tank capacity for the different seismic zone and also base moment supported on frame staging was less as compared to shaft staging.

\section{MATHODOLOGY}

It must be ensured that the design of water tank is capable for resistance of certainty like earthquake and wind loading, which varies with an increase in seismic zones.

\subsection{Methods of seismic analysis}

Mainly two different types of design analysis are as follows.

\subsubsection{Equivalent static analysis:}

Statistical approach can be efficiently appeal to elevated water tank. It is dependent on representation of seismic load in the form of identical static loads. Approximate in context to tank is vital and without any degradation, in accuracy estimate, a single degree of freedom is sufficient.

$$
\mathrm{K}=\mathrm{P} / \Delta
$$

Where

$\mathrm{K}=$ Lateral Stiffness of staging

$\mathrm{P}=$ Applied lateral force

$\Delta=$ Deflection in $\mathrm{mm}$

\subsubsection{Dynamic analysis:}

It is very hard to analyse the dynamic nature of elevated water tank. Due to static behaviour of tank, predictions can hardly be done. Elevated water tank having liquid with free surfaces 
related to motion of natural calamity like earthquake and the direction of motion result in acceleration of the tank wall and liquid. The liquid in the tank at lower region acts such a man that is stacked to wall. This is called impulsive mass of liquid $\left(\mathrm{m}_{\mathrm{i}}\right)$. Whereas liquid in tank at upper region is termed as convective mass of liquid $\left(\mathrm{m}_{\mathrm{c}}\right)$ due to sloshing motion.

For analysis of elevated tanks, whole structure is to be considered as two degree of freedom system includes of two uncoupled single degree of freedom systems that is impulsive and mass of structure act as an inverted pendulum having lateral stiffness equal to that of the staging, $\mathrm{K}_{\mathrm{s}}$ and the other is the convective phase with a spring of stiffness, $\mathrm{K}_{\mathrm{c}}$.

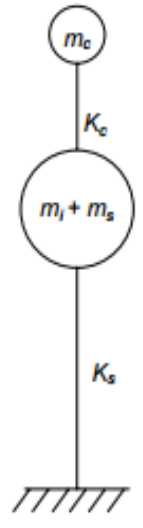

(a) Two degree of freedom system
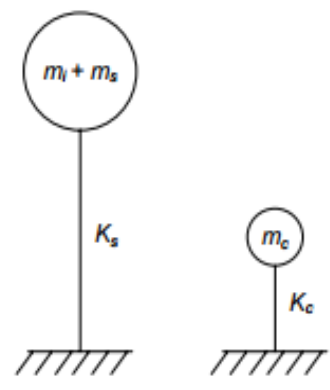

(b) Equivalent uncoupled system

Fig. 1 Two degree of freedom system of elevated water tank [13].

\subsubsection{Study Parameters}

Details of Constants data, dimensions of various elements, and detail of tank geometry are given in Table 1 and Table 2.

Table I: Constants data for Intze water tank

\begin{tabular}{|c|l|c|}
\hline S.No & \multicolumn{1}{|c|}{ Constants } & Value \\
\hline 1 & Volume of liquid & $250 \mathrm{~m}^{3}$ \\
\hline 2 & Materials & $\mathrm{M}-30 \& \mathrm{Fe} 415$ \\
\hline 3 & Unit weight $(\mathrm{RCC})$ & $25.01 \mathrm{kN} / \mathrm{m} 3$ \\
\hline 4 & $\mathrm{E}_{\mathrm{c}}$ & $\begin{array}{c}2.73 \times 10^{7} \\
\mathrm{kN} / \mathrm{m}^{2}\end{array}$ \\
\hline 5 & Seismic Zone $(\mathrm{Z})$ & $\mathrm{II}, \mathrm{III}, \mathrm{IV}, \mathrm{V}$ \\
\hline 6 & $(\mathrm{I})$ & 1.5 \\
\hline 7 & R & $2.5,3$ \\
\hline 8 & Soil Type & All \\
\hline
\end{tabular}

Table 2: Various component for intze water tank

\begin{tabular}{|l|l|c|}
\hline S.No & \multicolumn{1}{|c|}{ Elements } & Size (mm) \\
\hline 1 & Thickness of Dome at Top & 125 \\
\hline 2 & Dimension of Ring beam (at top) & $300 \times 450$ \\
\hline 3 & Thickness of RC wall (Cylindrical) & 220 \\
\hline 4 & Dimensions of Ring beam (at bottom) & $450 \times 450$ \\
\hline
\end{tabular}

\begin{tabular}{|l|l|c|}
\hline 5 & Circular Main Ring Beam & $600 \times 600$ \\
\hline 6 & Thickness of Dome (at Bottom) & 220 \\
\hline 7 & Thickness of Dome (Conical) & 300 \\
\hline 8 & Sizes of Bracings & $450 \times 450$ \\
\hline 9 & Diameter of Columns & 600 \\
\hline
\end{tabular}

Table 3 Lateral Stiffness of Frame Staging

\begin{tabular}{|l|l|c|}
\hline S.No & \multicolumn{1}{|c|}{ Height of staging } & \multicolumn{2}{|c|}{$\mathbf{K}_{\mathbf{s}}$} \\
\hline 1 & $16 \mathrm{~m}$ with 4 panels & $19380 \mathrm{kN} / \mathrm{m} 2$ \\
\hline 2 & $20 \mathrm{~m}$ with 4 panels & $11198 \mathrm{kN} / \mathrm{m} 2$ \\
\hline
\end{tabular}

In this research, results of elevated intze water tank carried out by using software i.e. STAAD Pro and MS excel, to determine the various forces such as base shear and base moments have been determined.

Seismic parameters have been determined for various type soil seismic zones, as consideration of single mass model according IS 1893 (Part-1) 2002 \& two mass model as per IS 1893 (Part-2) 2014. Empty tank condition was simulating for above consideration.

\section{RESULTS AND DISCUSSIONS}

4.1. Effect of Different Seismic Codes on Base Shear for both tank condition.

ㅁIS 1893 (Part-2):2014 ㅁIS 1893 (Part-1):2002

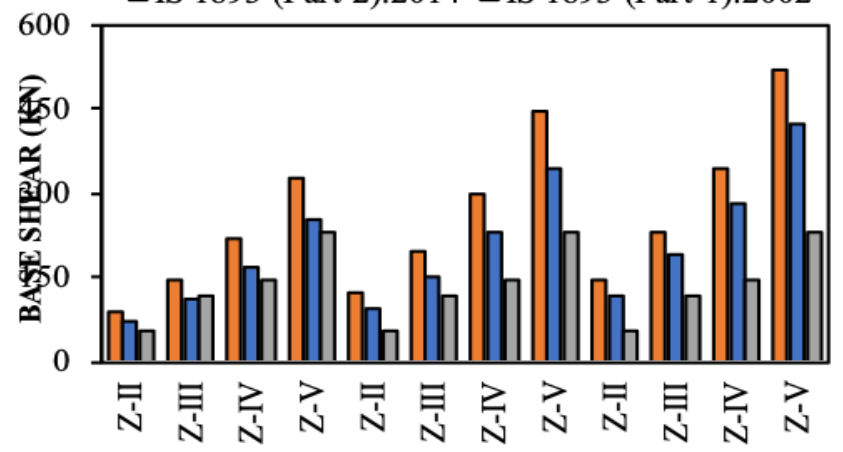

HARD SOIISENAGIPLEDNASIL SOQFTYSELL

Fig 2 Comparison of base shears from different seismic codes in different seismic zone and soil types for empty tank condition.

ㅁIS 1893 (Part-2):2014 ㅁIS 1893 (Part-1):2002

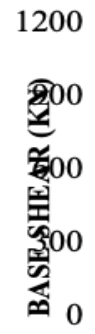


Fig 2 and 3 shows the variation of shear at base for these different seismic codes. It can be obtained from the Figs. that shear at base is less for IS 1893:1984 as compared to IS 1893 (Part-I): 2002 and IS1893 (Part-II): 2014 for empty and full tank type condition. Whereas, the shear at base is less for IS 1893 (Part-I): 2002 as compared to IS 1893 (part II): 2014 for empty tank condition, however, the base shear is more for IS 1893 (Part-I): 2002 as compared to IS 1893 (part II) 2014 for full tank condition.

It was observed from Figs. 2 that the base shear as per IS 1893:1984 was obtained less from 36\%, 34\%, 32\%, 30\% as compared to IS 1893 (Part-2): 2014 for seismic zones II, III, IV and V respectively in the case of rock soil and empty tank type condition. However, 53\%, 52\%, 48\%, $42 \%$ and $60 \%$, $58 \%, 55 \%, 50 \%$ less in base shear was also observed in the case of medium/soft soil and empty type tank condition.

As shown in from Figs. 3 that the base shear as per IS 1893-1984 was obtained less from 12\%, 10\%, 9\%, 3\% as compared to IS 1893 (Part-2) 2014 for seismic zones II, III, IV and V respectively in the case of rock soil and full tank condition. However, 36\%, 33\%, 28\%, $19 \%$ and $48 \%, 45 \%$, $42 \%, 34 \%$ less in base shear was also observed in the case of medium/soft soil and full tank condition.

It was also observed from Figs. 2 that the shear at base as per IS 1893 (Part-I): 2002 was obtained less from 23\% as compared to IS 1893 (Part-2): 2014 for II, III, IV and V seismic zones respectively in the case of rock soil/medium soil and empty tank type condition. However, 18\% less in base shear was also observed in the case of soft soil and empty tank condition.

As shown in from Figs. 3 that the base shear as per IS 1893 (Part-II): 2014 was obtained less from $26 \%$ as compared to IS 1893 (Part-I): 2002 for II, III, IV and V seismic zones respectively in all soil condition for full tank condition.

\subsection{Effect of Staging Height on Base Shear for both tank condition}

In this case, two staging height $16 \mathrm{~m}$ and $20 \mathrm{~m}$ were considered to analyze the base shear for medium soil condition. Fig 4 to 5 represents the variation of base shear for $16 \mathrm{~m}$ and $20 \mathrm{~m}$ staging height.

It was observed from Fig 4 that the base shear as per IS 1893:1984 was less by $17 \%$ for empty tank condition, similarly $11 \%$ less base shear was observed for full tank condition, when staging height is increased from $16 \mathrm{~m}$ to $20 \mathrm{~m}$ for all seismic zones in the case of medium soil type condition (Fig. 5).

It was also obtained from Fig 4 that the shear at base as per IS 1893 (Part-1): 2002 was less by $7 \%$ for empty tank condition, similarly $10 \%$ less base shear was observed for full tank condition, when staging height is increased from $16 \mathrm{~m}$ to $20 \mathrm{~m}$ for all seismic zones in the case of medium soil type condition (Fig. 5).

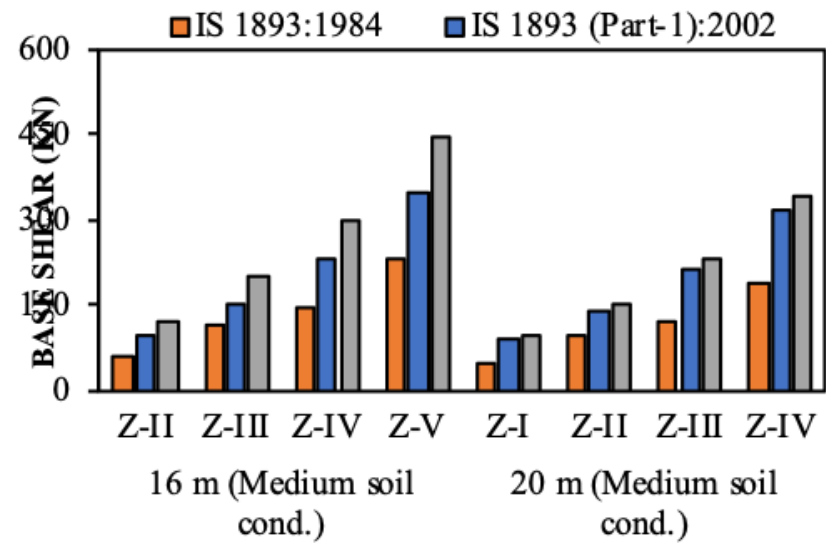

Fig. 4 Comparison of base shears from different seismic codes at different staging height for empty tank condition.

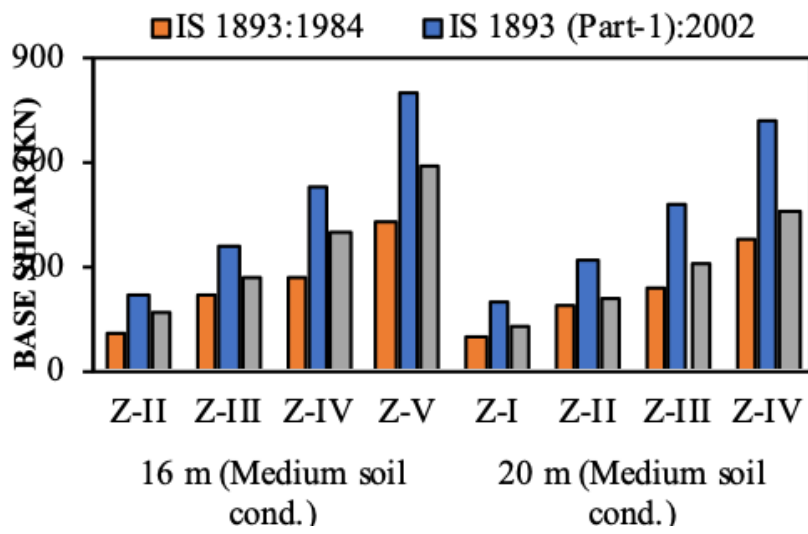

Fig. 5 Comparison of base shears from different seismic codes at different staging height for full tank condition. It was observed from Fig 4 that the base shear as per IS 1893 (Part-II): 2014 was less by $23 \%$ for empty tank condition, similarly percentage less base shear was observed for full tank condition, when staging height is increased from $16 \mathrm{~m}$ to $20 \mathrm{~m}$ for all seismic zones in the case of medium soil type condition (Fig. 5).

\subsection{Effect of Different Seismic Codes on Base Moment}

Fig 6 to 7 shows the variation in moment at base for different seismic codes. It can be found from the Figs. that moment at base is less for IS 1893:1984 as compared to IS 1893 (Part-I): 2002 and IS1893 (Part-II): 2014 for empty as well as full tank condition. Whereas, the base moment is less for IS 1893 (Part-I): 2002 as compared to IS 1893 (part II): 2014 for empty tank condition, however, the base moment is more for IS 1893 (Part-I): 2002 as compared to IS 1893 (part II) 2014 for full tank condition.

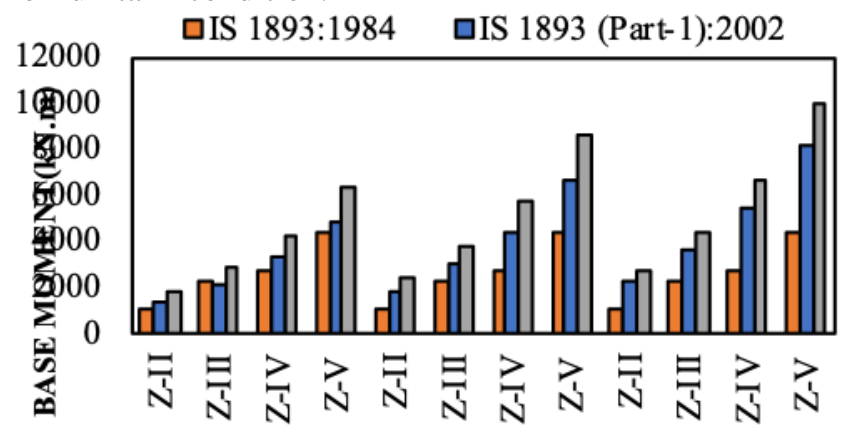

HARD SOIL MEDIUM SOIL SOFT SOIL

EMPLTMIIYNKODOSNOISQTITYPES

Fig 6 Comparison of base

Published By: 
moment from different seismic codes in various seismic zone and soil types for empty tank condition.

口IS 1893:1984

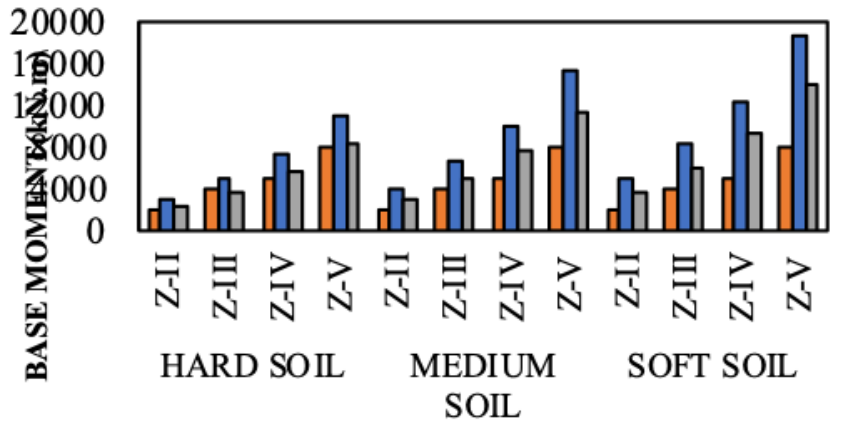

FSEISMHQXXOXONIYSOON TYPES

Fig. 7 Comparison of base shears from different seismic codes in various seismic zone and soil types for full tank condition.

It was observed from Figs. 6 that the base moment as per IS 1893:1984 was less from 36\%, 34\%, 32\%, 30\% as compared to IS 1893 (Part-2): 2014 for II, III, IV and V seismic zones respectively in the case of rock soil and empty tank type condition. However, $53 \%, 52 \%, 48 \%, 42 \%$ and $60 \%, 58 \%$, $55 \%, 50 \%$ less in base moment was also observed in the case of medium/ soft soil and empty tank condition.

As shown in from Figs. 7 that the base moment as per IS 1893-1984 was less from $12 \%, 10 \%, 9 \%, 3 \%$ as compared to IS 1893 (Part-2) 2014 for II, III, IV and V seismic zones respectively in the case of rock soil and full tank type condition. However, 36\%, 33\%, 28\%, $19 \%$ and 48\%, 45\%, $42 \%, 34 \%$ less in base moment was also observed in the case of medium/soft soil and full tank condition.

It was also obtained from Figs. 6 that the moment at base as per IS 1893 (Part-I): 2002 was less from $23 \%$ as compared to IS 1893 (Part-2): 2014 for II, III, IV and V seismic zones respectively in the case of hard soil/medium soil and empty tank type condition. However, $18 \%$ less in base moment was also observed in the case of soft soil and empty tank condition.

As shown in from Figs. 7 that the moment at base as per IS 1893 (Part-2): 2014 was less from 26\% as compared to IS 1893 (Part-I): 2002 for II, III, IV and V seismic zones respectively in all soil types and full tank condition because of that the horizontal seismic coefficient obtained less in impulsive/convective mode for IS 1893 (Part-II): 2014 as compared to IS 1893 (part II) 2002.

\subsection{Effect of Staging Height on Base Moment}

In this study, two staging height $16 \mathrm{~m}$ and $20 \mathrm{~m}$ were considered to analyze the base moment for medium soil condition. Fig 8 and 9 represents the variation of base moment for $16 \mathrm{~m}$ and $20 \mathrm{~m}$ staging height.

It was observed from Fig 8 that the base moment as per IS 1893:1984 was less by $17 \%$ for empty tank condition, similarly $11 \%$ less base moment was observed for full tank condition, when staging height is increased from $16 \mathrm{~m}$ to $20 \mathrm{~m}$ for all seismic zones in the case of medium soil type condition (Fig. 9).

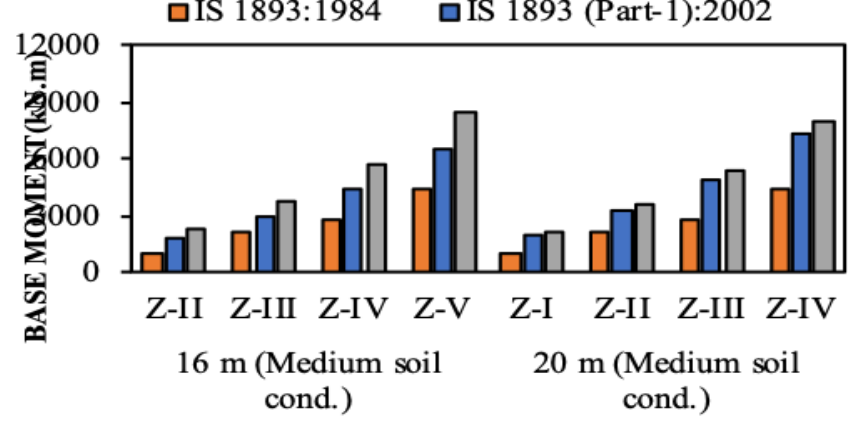

HEIGHT OF STAGING

Fig. 8 Comparison of base shears from different seismic codes at different staging height for empty tank condition.

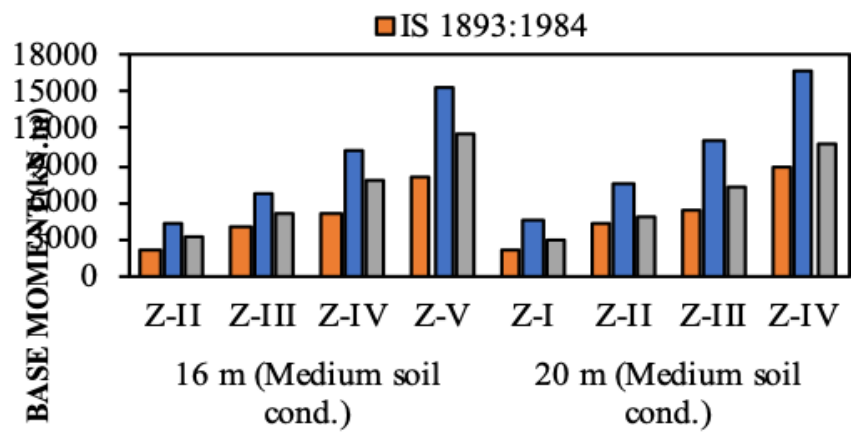

HEIGHT OF STAGING

Fig. 9 Comparison of base shears from different seismic codes at different staging height for full tank condition. It was also obtained from Fig 8 that the moment at base as per IS 1893 (Part-1): 2002 was less by 7\% for empty tank condition, similarly $10 \%$ less base moment was observed for full tank condition, when staging height is increased from $16 \mathrm{~m}$ to $20 \mathrm{~m}$ for all seismic zones in the case of medium soil type condition (Fig. 9).

It was observed from Fig 8 that the base moment as per IS 1893 (Part-II): 2014 was less by 23\% for empty tank condition, similarly percentage less base moment was observed for full tank condition, when staging height is increased from $16 \mathrm{~m}$ to $20 \mathrm{~m}$ for all seismic zones in the case of medium soil type condition (Fig. 9).

4.5 Effect of Hydrodynamic pressure in various seismic zone and soil condition

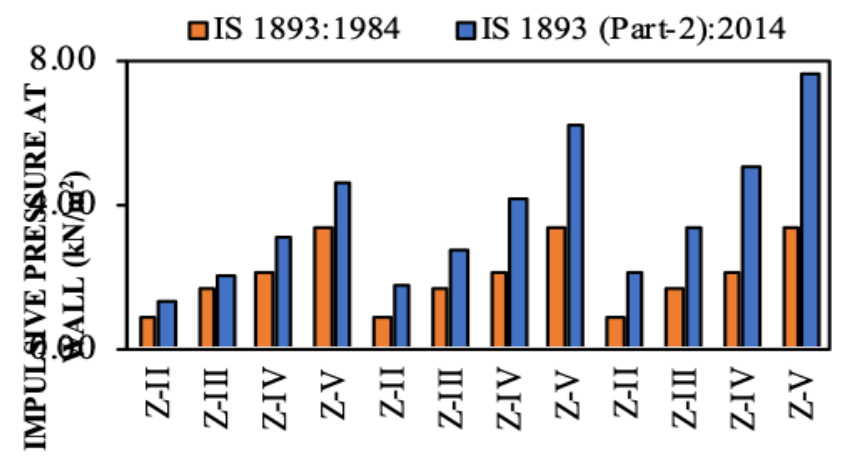

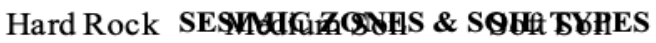

Fig. 10 Comparison hydrodynamic Impulsive pressure on wall from various seismic zones for empty tank condition. 
Fig. 10 and 11 represents the variation of hydrodynamic impulsive pressure at base slab and wall for different zones. It is observed that the hydrodynamic impulsive pressure at base slab and wall increased as the zone factor increases. It was also observed from Figs. 10 that the impulsive hydrodynamic pressure increased by $100 \%, 150 \%, \& 300 \%$ for seismic zone III, IV \& V as compared to seismic zone II for IS 1893: 1984 respectively on wall. Similarly, increase in impulsive hydrodynamic pressure was also observed when pressure is at base (Fig. 11).

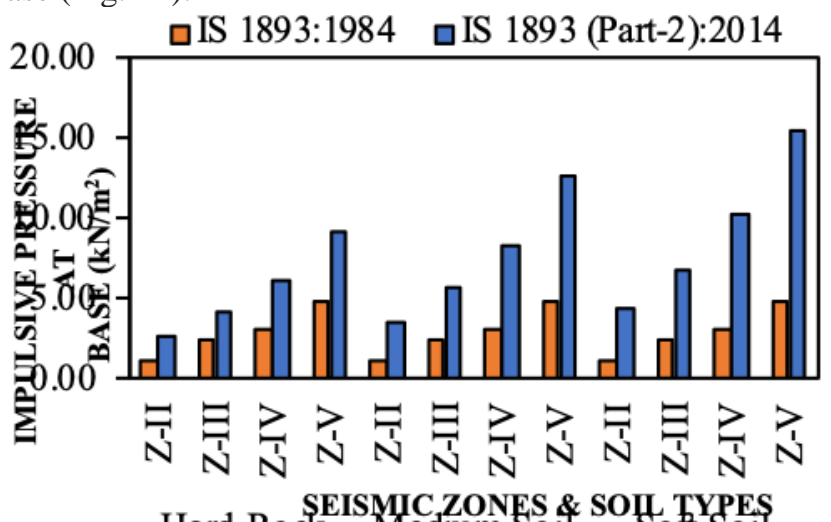

Fig. 11 Comparison Impulsive hydrodynamic pressure on wall from various seismic zones for full tank condition.

It was observed form Figs. 10 that the impulsive hydrodynamic pressure increased by $60 \%, 140 \%$, \& $260 \%$ for seismic zone III, IV \& V as compared to zone II for IS 1893 (Part-II): 2014 respectively on wall. Similarly, increase in impulsive hydrodynamic pressure was also observed when pressure is at base (Fig. 11).

It was also observed form Figs. 12 that the convective hydrodynamic pressure increased by $56 \%, 137 \%$, \& $256 \%$ for seismic zone III, IV \& V as compared to zone II for IS 1893 (Part-II): 2014 respectively on wall. Similarly, increase in convective hydrodynamic pressure was also observed when pressure is at base (Fig. 13).

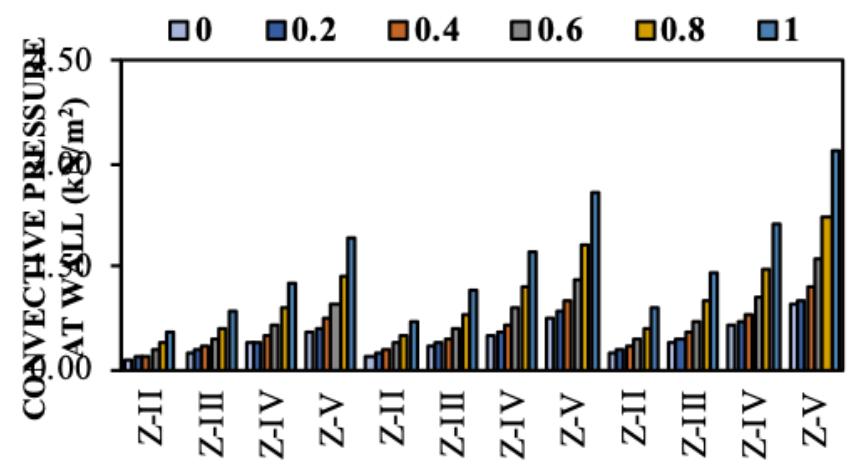

Hard Rock Medium Soil Soft Soil

SEISMIC ZONES \& SOIL TYPES

Fig. 12 Comparison convective hydrodynamic pressure at wall in various seismic zones as per IS 1893 (Part-II): 2014.

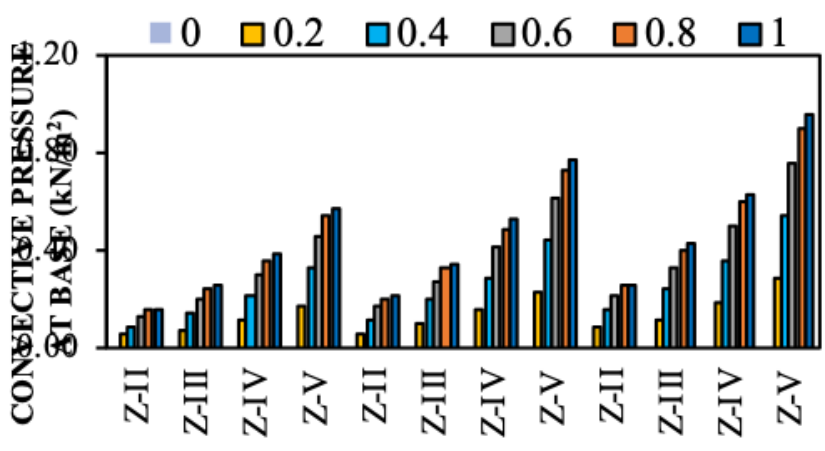

Hard Rock Medium Soil Soft Soil SEISMIC ZONES \& SOIL TYPES

Fig. 13 Comparison convective hydrodynamic pressure at base in various seismic zones as per IS 1893 (Part-II): 2014.

\section{CONCLUSION}

According to the analytical results and discussions, the following conclusion can be taken as:

- The shear and moment at base increase with increasing design horizontal seismic coefficient $(\alpha \mathrm{h})$ which depends on seismic zone factor. Shear and moment at base increase in the range of $59 \%-301 \%$ for seismic zone III, IV \& V as compared to seismic zone II respectively for both tank conditions.

- Soft soil condition is more severe than medium and hard soil condition. Base shear and base moment increase by $36 \%$ and $67 \%$ for medium and soft soil as compared to hard soil as per IS 1893 (Part-I) 2002 /IS 1893 (Part-II) 2014 for all seismic zones for both tank condition.

- Base shear and base moment do not vary when soil changed from rock to soft soil as per IS 1893-1984 for both tank condition.

- Shear and moment at base are found less for IS 1893:1984 as compared to IS 1893 (Part-II): 2014 for empty as well as full tank type condition. However, the shear and moment at base are obtained less for IS 1893 (Part-II): 2014 as compared to IS 1893 (part II) 2002 for full tank condition.

- Base shear and base moment as per IS 1893:1984, IS 1893 (Part-I): 2002 and IS 1893 (Part-II): 2014 are obtained less by $17 \%, 7 \%$ and $23 \%$ respectively for empty tank condition, similarly $11 \%, 10 \%$ and $23 \%$ less shear and moment at base are observed for full tank type condition, when staging height is increased from $16 \mathrm{~m}$ to $20 \mathrm{~m}$ for all seismic zones in the case of medium soil condition.

- Impulsive hydrodynamic pressure increases with increasing design horizontal seismic coefficient $(\alpha h)$ which depends on seismic zone factor. Impulsive hydrodynamic pressure increases by $300 \%$ and $260 \%$ for seismic zone V as compared to seismic zone II for IS 1893: 1984 and IS 1893 (Part-II): 2014 respectively on wall. Similarly, percentage increase in impulsive hydrodynamic pressure is also observed when pressure acts at base.

- Convective hydrodynamic pressure increases by $256 \%$ for seismic zone V as compared to zone II for IS 1893 (Part-II): 2014 respectively on wall. Similarly, Percentage increase in

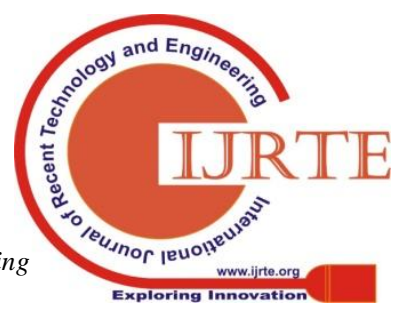


convective hydrodynamic pressure is also observed when pressure is at base.

\section{REFERENCES}

1. G. Madhukar and M. Madhuri, "Seismic Performance of Circular Elevated Water with Framed Staging", International Journal of advanced research in Engineering and Technology, 4(4), 2013, 159-167.

2. M. S. Mhetre and G. R. Patil, "Analysis of Elevated Water Storage Structure Using Different Staging System", IOSR Journal of Mechanical and Civil Engineering (IOSR-JMCE), 2(6), 2015, 21-32.

3. S.K. Jain and S.U. Sajjad, "A Review of the requirement in Indian codes for a seismic design of Elevated water tanks", The Bridge and Structural Engineering, 12(1), 1993, 1-15.

4. K Harsha, K. S. K Reddy and S.K Kala, "Seismic Analysis and Design of Intze Type Water tank", International Journal of Science Technology and Industrial Engineering, 2(3), 2015, 11-24.

5. O. R Jaiswal. and S. K Jain, "Modified Proposed Provisions for a Seismic Design of Liquid Storage Tanks: Part II-Commentary and Examples", Journal of Structural Engineering, 32(4), 2005, 297-310.

6. IS 1893 (Part-2) "Criteria for Earthquake Resistant Design of Structures Part 2 Liquid Retaining Tanks”, Bureau of Indian Standards, New Delhi, 2014.

7. J. Lakhankiya and H. J Shah, "A Parametric Study of an Intze Tank Supported on Different Staging", International Journal for Science Research in Engineering and development, 3(9), 2015, 1108-1112.

8. R. Livaoglu and A Dogangün, "Effect of Foundation Embedment on Seismic Behavior of Elevated Tanks considering Fluid- Structure-Soil Interaction", First International Conference on Seismology and Earthquake Engineering (SEE), 27(1), 2007, 855-863.

9. H. Shakib, F Omidinasab, and M. T Ahmadi, "Seismic Demand Evaluation of Elevated Reinforced Concrete Water Tanks", International Journal of Civil Engineering, 8(3), 2010, 204-220.

10. K. Vyankatesh and T. Varsha, "Comparative study on dynamic analysis of elevated water tank frame staging and concrete shaft supported", IOSR Journal of Mechanical and Civil Engineering (IOSR-JMCE), 14(1), 2017 38-46.

11. IS 1893 (Part-1) "Criteria for Earthquake Resistant Design of Structures", Bureau of Indian Standards, New Delhi, 2002.

12. S Nerkar. and C Nayak, "Seismic Behavior of Elevated Storage Reservoir by Finite Element Method", International Conference on Recent Innovation in Engineering and Management, 4(3), 2016, 1188-1197.

13. IS 1893 (Part-2): 2014. Criteria for Earthquake Resistant Design of Structures Part 2 Liquid Retaining Tanks. Bureau of Indian Standards New Delhi.

\section{AUTHORS PROFILE}

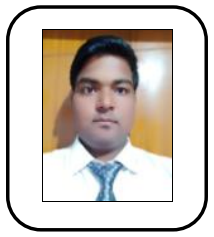

Mr. Rakesh Yadav: Author is presently working as an Assistant Professor in Department of Civil Engineering, Techno India NJR Institute of Technology, Udaipur since 2017. He has done his BE and MTech from College of Technology and Engineering, Udaipur. His research area is Analysis \& Design of RCC and steel Structures and Concrete Technology. 